\title{
Uncommon cause of cervicobrachial neuralgia: epidural abscess complicating tuberculous arthritis
}

Sami Kouki, ${ }^{1}$ Manel Landolsi, ${ }^{1}$ Mehdi Ben Lassoued, ${ }^{2}$ Imen Gharsallah ${ }^{3}$

'Department of Radiology, Hopital Militaire Principal d'Instruction de Tunis, Universite de Tunis El Manar Faculte de Medecine de Tunis, Tunis, Tunisia ${ }^{2}$ Department of Emergency, Military Hospital Tunisia, Tunis, Tunisia

${ }^{3}$ Department of Rheumatology, Military Hospital of Tunis, University of Tunis El Manar, Tunis, Tunisia

\section{Correspondence to} DrSami Kouki, koukisemi@ yahoo.fr

Accepted 20 June 2017

\section{DESCRIPTION}

A 59-year-old patient was admitted to the rheumatology department with cervicobrachial neuralgia in the upper extremities and paresthesia. The symptoms appeared 3 months ago.

Physical examination showed neck stiffness with decreased sensitivity in the territory of the $\mathrm{C} 4$ root in both arms. There was no motor weakness or fever. The inflammatory blood markers were increased.

Spinal MRI was performed showing posterior epidural collection hyperintense in T2-weighted images (figure 1) with intense peripheral enhancement extending from C3-C4 to C4-C5 (figure 2). A facet joint arthritis at the level of C3-C4 was also noticed with a T2 hyperintense lesion of the spinal cord (figure 1).

The patient was immediately referred to surgery. The surgical treatment consisted of cervical laminotomy with drainage of the epidural collection. The culture of the abscess fluid revealed Mycobacterium tuberculosis. Long-lasting antituberculosis treatment was prescribed in addition to surgical treatment.

Cervical facet joint arthritis with epidural abscess is a rare condition. ${ }^{1}$ Itusually occurs after a local infection, trauma or surgical procedure. ${ }^{12}$ Patients with immunodeficiency and diabetes mellitus are often concerned. The most involved germ is Staphylococcus aureus. ${ }^{3}$ The epidural abscess can be responsible for

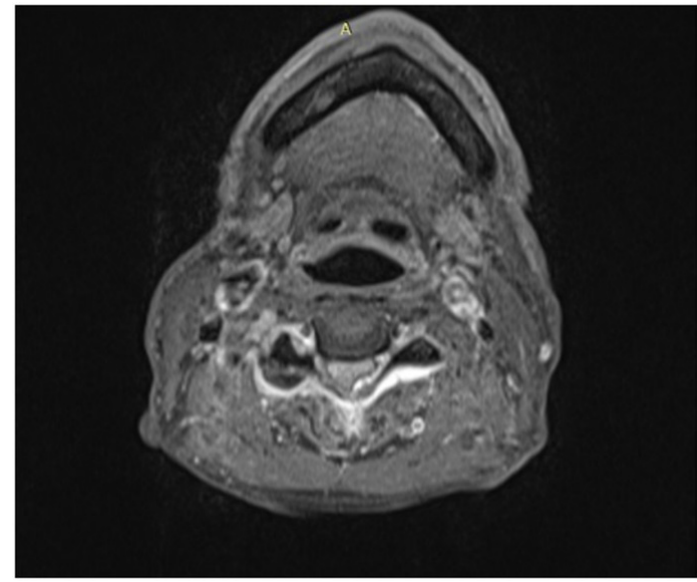

Figure 2 T1FAT SAT post-gadolinium axial images showing intense facet joints enhancement with epidural posterior collection.

spinal cord compression or nerve root impingement.

The management of cervical arthritis and epidural abscess is controversial. Some authors recommend starting with intravenous antibiotherapy especially in patients without medical history. Other associate antibiotics and CT-guided drainage of the epidural abscess. ${ }^{3}$ Surgical treatment is needed in case of medullar
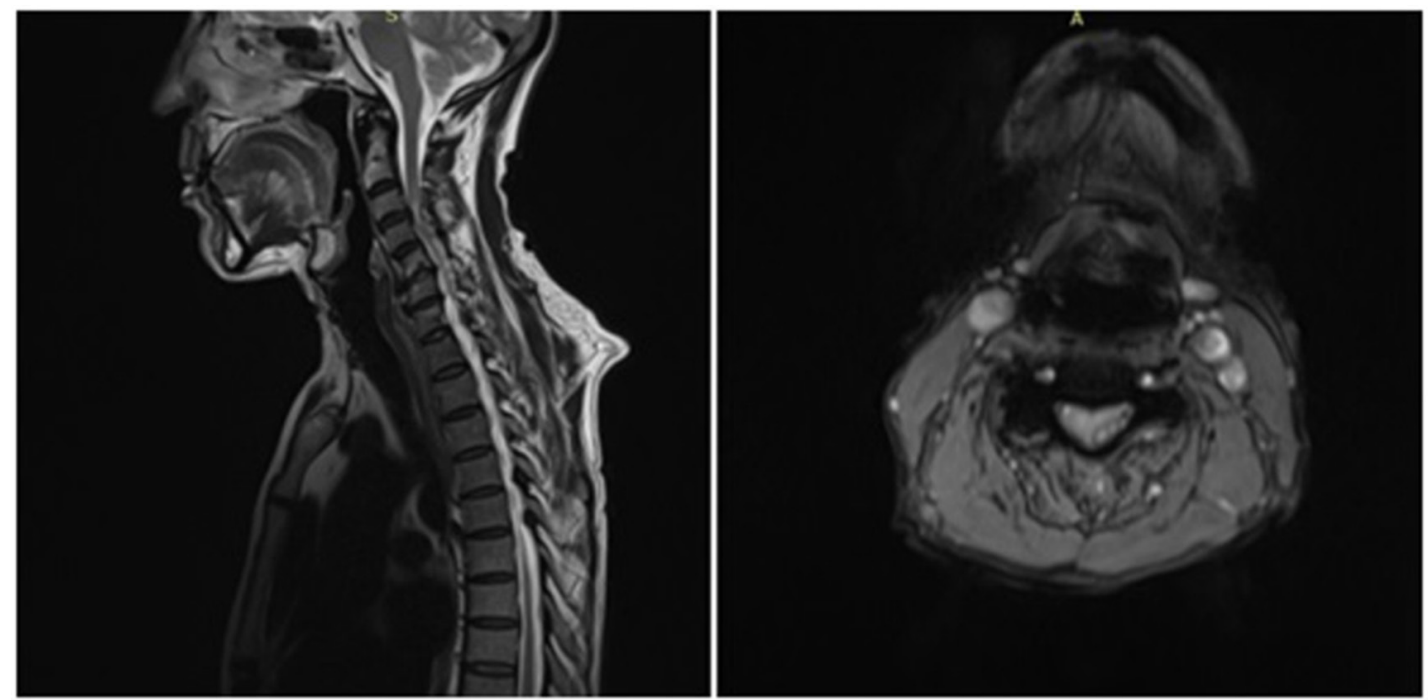

Figure 1 T2-weighted sagittal and axis images showing posterior epidural mass with mass effect on the spinal cord at C3-C4 and medullar oedema. 


\section{Learning points}

- Facet joint cervical arthritis is a rare condition. It is evoked in the case of cervical pain with neck stiffness especially in patients with immunodeficiency and diabetes mellitus. Cervicobrachial neuralgia is an uncommon revealing symptom.

- Spinal cord compression by an epidural abscess is suspected in the case of sensitive and motor deficiencies. Spinal MRI is then needed to detect epidural collections and look for medullar oedema.

- The treatment of facet joint cervical arthritis depends on the responsible organism. Staphylococcus aureus is the most frequently involved germ requiring intravenous antibiotherapy. Mycobacterium tuberculosis is rarely involved and requires specific antituberculosis drugs. In the case of medullar compression, surgical treatment is needed allowing to remove epidural abscess and to discharge the spinal cord. compression; it allows to remove the abscess discharging from the spinal cord.

Contributors SK: author of the article. ML: coauthor participation in writing and bibliography. IG: provided follow-up. MBL: examined the patient in the emergency room

Competing interests None declared.

Patient consent Obtained.

Provenance and peer review Not commissioned; externally peer reviewed.

(C) BMJ Publishing Group Ltd (unless otherwise stated in the text of the article) . All rights reserved. No commercial use is permitted unless otherwise expressly granted.

\section{REFERENCES}

1 Al-Hourani K, Al-Aref R, Mesfin A. Upper Cervical Epidural Abscess in clinical practice: diagnosis and management. Global Spine J 2016:6:383-93.

2 Arko L, Quach E, Nguyen V, et al. Medical and surgical management of spinal epidural abscess: a systematic review. Neurosurg Focus 2014;37:E4.

3 Liou LM, Shih PY. Epidural abscess of the cervical spine with atypical manifestations: a report of two cases. Neurologist 2007;13:215-8.

Copyright 2017 BMJ Publishing Group. All rights reserved. For permission to reuse any of this content visit http://group.bmj.com/group/rights-licensing/permissions.

BMJ Case Report Fellows may re-use this article for personal use and teaching without any further permission.

Become a Fellow of BMJ Case Reports today and you can:

- Submit as many cases as you like

- Enjoy fast sympathetic peer review and rapid publication of accepted articles

- Access all the published articles

- Re-use any of the published material for personal use and teaching without further permission

For information on Institutional Fellowships contact consortiasales@bmjgroup.com

Visit casereports.bmj.com for more articles like this and to become a Fellow 